\title{
Aplicaciones alternas de insecticidas químicos y botánicos para el manejo de mosca blanca (Bemisia tabaci, Gennadius) y Geminivirus en tomate (Solanum lycopersicum L.) en Tisma, Nicaragua
}

\section{Chemical insecticides alternating with botanical insecticides as management options of whitefly (Bemisia tabaci, Gennadius) and Geminivirus in tomato (Solanum lycopersicum L.) in Tisma Nicaragua}

\author{
Edgardo Jiménez-Martínez ${ }^{1}$, Jordan Balladares Balladares ${ }^{2}$ \\ ${ }^{1} \mathrm{PhD}$ en Entomología, ORCID: https://orcid.org/0000-0003-1086-7380, Universidad Nacional Agraria, profesor titular, edgardo.jimenez@ \\ ci.una.edu.ni \\ ${ }^{2}$ Ingeniero Agrónomo.
}

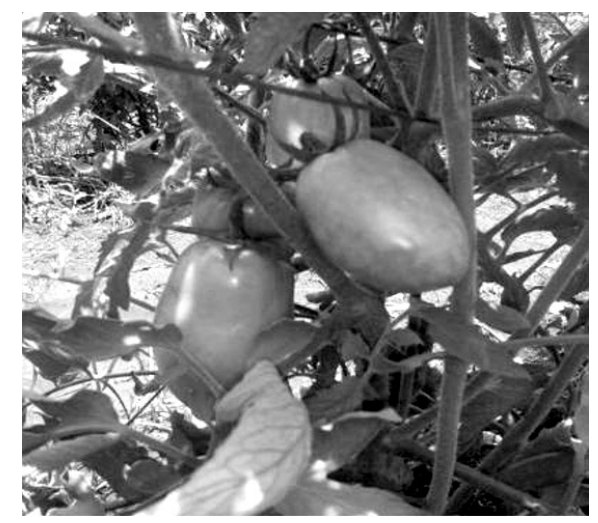

\section{RESUMEN}

La mosca blanca (Bemisia tabaci, Gennadius.) y los Geminivirus son los principales agentes de daño causantes de problemas fitosanitarios severos para los productores de tomate (Solanum lycopersicum, L.). Este insecto provoca importantes pérdidas económicas, disminuyendo los rendimientos al afectar la calidad de frutos. En base a esta situación se realizó un estudio en el municipio de Tisma, Masaya en el período comprendido entre julio y septiembre del 2015 para evaluar la efectividad de insecticidas químicos alternados con botánicos para el manejo de la mosca blanca y su daño causado por virosis. Los tratamientos evaluados fueron: Engeo ${ }^{\circledR}$ alternado con Chile+Ajo+detergente, Imidacloprid ${ }^{\circledR}$ alternado con Madero Negro, Abamectina ${ }^{\circledR}$ alternado con Neem, Monarca ${ }^{\circledR}$ alternado con Chile+ajo y un testigo que consistió en aplicaciones de agua solamente. Las variables evaluadas fueron, número de mosca blanca por planta, incidencia y severidad del daño de virosis por planta, rendimiento en $\mathrm{kg} \mathrm{ha}^{-1}$. De los tratamientos evaluados, el menor número de moscas blancas, menor porcentaje de incidencia y severidad del daño de virosis y mayor rendimiento lo presentó el tratamiento Abamectina ${ }^{\circledR}$ alternado con Neem, seguido de Monarca ${ }^{\circledR}$ alternado con chile+ajo. Se concluye que Abamectina ${ }^{\circledR}$ alternado con Neem es el tratamiento que resultó más efectivo para el manejo de mosca blanca y su daño por virosis.

Palabras clave: insectos vectores, plaguicidas, solanaceas.

\begin{abstract}
The whitefly (Bemisia tabaci, Gennadius.) and Geminiviruses are the main agents of damage causing severe phytosanitary problems for tomato producers (Solanum lycopersicum, L.). This insect causes significant economic losses, decreasing yields by affecting the quality of fruits. Based on this situation, a study was conducted in the municipality of Tisma, Masaya in the period between july and september 2015 to evaluate the effectiveness of alternating chemical insecticides with botanists for the management of the whitefly and its damage caused by viruses. The evaluated treatments were: Engeo ${ }^{\circledR}$ alternated with Chili+Garlic+detergent, Imidacloprid ${ }^{\circledR}$ alternated with Madero Negro, Abamectina ${ }^{\circledR}$ alternated with Neem, Monarca ${ }^{\circledR}$ alternated with Chili+garlic and a control consisting of water only applications. The evaluated variables were, number of whitefly per plant, incidence and severity of virus damage per plant, yield in $\mathrm{kg} \mathrm{ha}^{-1}$. Of the treatments evaluated, the lower number of white flies, lower percentage of incidence and severity of virus damage and higher yield was presented by the Abamectina ${ }^{\circledR}$ treatment alternated with Neem, followed by Monarca ${ }^{\circledR}$ alternated with chili+garlic. It is concluded that Abamectina ${ }^{\circledR}$ alternated with Neem is the treatment that was most effective for the management of whitefly and its damage by virus.
\end{abstract}

Key words: Vector borne insects, pesticides, solanaceas.
Recibido: 8 de noviembre del 2018 Aceptado: 20 de febrero del 2019

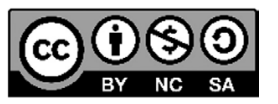

Los artículos de la revista La Calera de la Universidad Nacional Agraria, Nicaragua, se comparten bajo términos de la licencia Creative Commons: Reconocimiento, No Comercial, Compartir Igual. Las autorizaciones adicionales a las aquí delimitadas se pueden obtener en el correo edgardo.jimenez@ci.una.edu.ni

C Copyright 2019. Universidad Nacional Agraria 


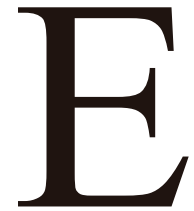

1 tomate $($ Solanum lycopersicum $\mathrm{L} .=$ Lycopersicum esculentum, Mill.), es originario del sur de América, específicamente de la región andina (Perú, Bolivia y Ecuador), aunque el centro de domesticación fue el sur de México y el norte de Guatemala donde existe el mayor grado varietal de la planta (INTA, 2004). En Nicaragua el tomate es una de las hortalizas de mayor producción e importancia económica para los productores, se destina principalmente para consumo interno y en menor proporción se destina a la exportación a algunos países de Centroamérica, principalmente a El Salvador, para la alimentación de todos los nicaragüenses es la hortaliza más importante, comestible en ensaladas y salsas, como condimento y en su estado verde, también los utilizamos en encurtidos y conservas. A nivel de industria de enlatados lo utilizan deshidratado o procesado para sopas, pasta y jugos (INTA, 2002). Taxonómicamente el tomate pertenece a la familia Solanáceae y a la especie Lycopersicum, esta es una planta perenne de porte arbustivo que se cultiva como anual, puede desarrollarse de forma rastrera, semierecta o erecta; existen variedades de crecimiento limitado e indeterminado (Rayo, 2001). El cultivo de tomate inició en Nicaragua en los años 1940 en el municipio de Tisma, departamento de Masaya, este es un cultivo de mucha importancia a nivel mundial ya que es un producto que sirve de materia prima en la agro-industria y, además, está presente en la mayoría de los menús culinarios, debido a su valor nutritivo y al alto contenido de vitaminas A y C (CATIE, 1990).

El tomate es cultivado principalmente por pequeños y medianos productores de los departamentos de Matagalpa y Jinotega, particularmente en los Valles de Sébaco y Tomatoya; también, se produce en zonas de Estelí, Malacatoya, Tisma y Nandaime. Todas las zonas mencionadas tienen áreas potenciales para el cultivo mucho más extensas de las que se cultivan. Existen además otras zonas con potencial, como el Valle de Jalapa, la meseta de Carazo y algunos valles intra-montañosos de los departamentos de Boaco y Chontales (MIFIC, 2007). El tomate es una planta que tolera mucho la defoliación durante la etapa de crecimiento vegetativo sin afectar el rendimiento. Este alto grado de tolerancia y al hecho de que varias plagas del tomate son secundarias provocadas por el uso excesivo de insecticidas, indica que es esencial minimizar el uso de productos de amplio espectro durante la etapa en la cual el cultivo es tolerante, esta acción nos ayuda a preservar los enemigos naturales de las plagas que se pueden presentar a lo largo del ciclo del cultivo (Jiménez-Martinez y Rodríguez, 2014). Los principales daños que sufre el cultivo hacen referencia en problemas fitosanitarios a lo largo de su ciclo biológico, que pueden afectar los rendimientos de manera significativa si no son tratados a tiempo y por tanto ocasionar pérdidas económicas considerables en las familias productoras (INTA, 2004). Uno de los problemas que resal- ta es el daño causado por los geminivirus transmitidos por mosca blanca de los biotipos A y B, vector de varios virus a nivel mundial (Ríos y Somarriba, 2014). Se han reportado diferentes tecnologías como solución al problema, tales como el uso de micro-invernadero en la etapa de semillero, uso de insecticidas sintéticos y prácticas culturales en la etapa de campo, sin embargo, la problemática de la plaga aún persiste (Cerda y Jiménez-Martinez, 2012).

En el municipio de Tisma donde el tomate se establece en forma de monocultivo se reportan pérdidas de hasta un $50 \%$ del total de cosecha de tomate, ocasionadas por los geminivirus, convirtiéndose en el principal problema fitosanitario del tomate (Jarquín, 2004), por tanto, se hace urgente encontrar alternativas de manejo que sean efectivas, accesible a los productores del municipio y que no ocasionen efectos negativos en el ambiente. En base a esta situación se realizó un estudio para evaluar la efectividad que tienen la alternancia de productos químicos seguidos de insecticidas botánicos para el manejo del complejo mosca blanca-virus en tomate. Se pretende con esta investigación determinar con cuál de las alternativas en estudio el cultivo presenta mayor tolerancia al ataque de mosca blanca y otras plagas, logrando poner en mano de los productores una tecnología que le permita mantener las poblaciones de mosca blanca en niveles que no ocasionen pérdidas económicas y así mismo que disminuyan sus costos de producción.

\section{MATERIALES Y MÉTODOS}

Ubicación del área de estudio. El estudio se realizó en la finca El Chagüite, propiedad de la señora Elizabeth González. La finca se encuentra ubicada en el municipio de Tisma, departamento de Masaya, Nicaragua a $36 \mathrm{~km}$ de distancia de la capital y en las coordenadas geográficas $12^{\circ} 04^{\prime}$ de latitud Norte y $86^{\circ} 01^{\prime}$ de longitud Oeste. Posee una superficie de $126.17 \mathrm{~km}^{2}$ con una población de 10681 habitantes (González y Obregón, 2007). Tisma se encuentra a una altitud de 50 msnm, presenta un clima que se caracteriza por ser tropical de sabana, con temperaturas promedios de $27.5^{\circ} \mathrm{C}$ y con precipitaciones pluviales anuales que oscilan entre los 1200 y 1 $400 \mathrm{~mm}$ (AMUNIC, 2005).

Establecimiento del ensayo. El ensayo se estableció el ocho de julio y culminó con la última cosecha el 30 de septiembre del 2015, antes de establecer el ensayo en campo se realizó un semillero de tomate cuya fecha de siembra fue el 14 de junio del 2015, bajo condiciones de micro invernadero, usando bandejas de plástico de 96 celdas donde se depositaron las semillas. El sustrato utilizado fue $50 \%$ tallo de coco molido y $50 \%$ humus de lombriz en proporción 1:1. El híbrido de tomate utilizado fue Shanty el cual posee alta tolerancia al TYLCV (Virus de la hoja enrollada amarilla del tomate) y un potencial de rendimiento muy alto, es un tomate grande 
cuyo peso del fruto varía de 120 a 150 gramos, de color rojo intenso y de larga vida de anaquel. Las plántulas fueron tratadas con dos aplicaciones de Sulfato de Cobre pentahidratado (Phyton $\left.{ }^{\circledR}\right)$, fungicida-bactericida sistémico. Utilizando dosis de $4 \mathrm{~cm}^{3}$ por litro de agua.

Diseño experimental. Se utilizó un diseño de BCA (Bloques Completos al Azar), con tres repeticiones y cinco tratamientos los que consistían en plaguicidas químicos alternados con preparados botánicos y un testigo que consistía en la aplicación de agua solamente. Los plaguicidas se alternaban con los botánicos cada tres o cuatro días dependiendo del muestreo de plagas. Para este ensayo se estableció una parcela en forma rectangular, cuyas dimensiones fueron de seis metros de largo y tres $m$ de ancho para un área por tratamiento de $18 \mathrm{~m}^{2}$, para un total de área por bloque de $90 \mathrm{~m}^{2}$ y un área total del experimento de $408 \mathrm{~m}^{2}$. Se utilizaron distancias de siembra de 0.4 metros entre planta y entre surco 1.5 metro, con un total de nueve surcos y 75 plantas por surco, para un total de 675 plantas en toda la parcela y un total de 16544 plantas por hectárea.

Muestreo de insectos. Para determinar el momento de la aplicación de los tratamientos se realizaron muestreos semanales por la mañana de 7:00 a 9:00 am en 25 plantas al azar por tratamiento para un total de 375 pantas en todo el ensayo.

Aplicación de plaguicidas. Los plaguicidas se alternaban con los preparados botánicos cada 3 ó 4 días dependiendo del muestreo de adultos de mosca blanca por cada tratamiento, se utilizó un nivel crítico poblacional de 0.5 mosca blanca por planta como parámetro de decisión (Ríos y Somarriba, 2014), debido a que por encima de este nivel crítico las plagas alcanzan el NDE (Nivel de Daño Económico). Las aplicaciones fueron por aspersión directa al follaje haciendo uso de bomba de mochila, Matabi ${ }^{\circledR}$ con capacidad de 20 litros de agua.

\section{Tratamientos evaluados}

Tratamiento 1: Engeo alternado con chile+ajo+detergente Engeo ${ }^{\circledR}$ : (Thiametoxam 25\% y lambda-cihalotrina 10.6\%). Es un insecticida de amplio espectro de acción, especialmente indicado para el control de larvas y adultos de insectos masticadores y chupadores. Engeo $247 \mathrm{SC}$ actúa por contacto, con un rápido poder de volteo, por ingestión, y también posee efecto de repelencia y acción anti-alimentaria. Complementario a esto, su actividad sistémica le permite controlar plagas que se alimentan de los contenidos celulares (Syngenta, 2015). La dosis utilizada fue de $3 \mathrm{~cm}^{3}$ por litro de agua.

Chile (Capsicum sp) Fam. Solanaceae + ajo (Allium sativum L.) Fam. Amaryllidaceae + detergente del tipo Xedex ${ }^{\circledR}$. El chile contiene el ingrediente activo llamado Capcicina, este actúa inhibiendo el apetito de los insectos, sus principios activos se sitúan en la cáscara y las semillas. Este libera una toxina que actúa como repelente y desvía los hábitos alimenticios por el contacto o la ingestión que altera el sistema nervioso (Arceda y López, 2011). El ajo posee propiedades de repelencia para mosca blanca por el contenido de extracto gárlico y tiosulfato provocando desorientación (Cerda, 2011). El detergente, es utilizado como adherente e insecticida de contacto. Para la preparación de este producto se maseraron 100 gramos o cuatro onzas de chile molido (cascara y semilla madura), 1 cabeza de ajo, luego se pone a fermentar la mezcla en un litro de agua durante 24 horas. Posteriormente se cuela la preparación y se envasa agregándole una onza de detergente. La dosis es de un litro de la mezcla por bomba de 20 litros (Jiménez-Martínez y Varela, 2012).

Tratamiento 2: Imidacloprid alternado con madero negro Imidacloprid (Confidor ${ }^{\circledR} 20$ LS). Es un formulado a base de imidacloprid, materia activa perteneciente al grupo químico de los cloronicotinilos, cuyas excelentes propiedades insecticidas se basan en el bloqueo de los impulsos nerviosos de los insectos. Actúa tanto por contacto como por ingestión, lo que, unido a sus excelentes propiedades sistémicas y elevada actividad residual, hace que tenga un amplio espectro de acción, especialmente contra insectos chupadores (Bayer CropScience, $2016 \mathrm{~b}$ ). La dosis utilizada fue de $5 \mathrm{~cm}^{3}$ por litro de agua.

Madero negro (Gliricidia sepium Jacq), Fam. Fabaceae. Es un insecticida y abono foliar que contiene flavonoides, su toxicidad para insectos se debe a la conversión por las bacterias de cumarinas a dicoumerol durante la fermentación (Lanuza y Rizo, 2012). Es un insecticida de contacto e ingestión, además actúa como repelente ante los insectos. Para su elaboración se trituró una libra de hojas de madero negro en dos litros de agua y se dejó reposar por 24 horas. La dosis de aplicación es de un litro del producto elaborado por bomba de 20 litros litros (Jiménez-Martinez y Varela, 2012).

Tratamiento 3: Abamectina alternado con extracto de neem Abamectina (VERTIMEC $® 018$ EC). Es un acaricida-insecticida de origen natural, con poderosa actividad translaminar, producido por el microorganismo del suelo Streptomyces avermitilis. Actúa principalmente por ingestión y contacto directo. El ácaro o insecto se paraliza, no se alimenta y no ovipone, y dentro de un corto tiempo muere. VERTIMEC $₫$ 018 EC penetra en el tejido de la planta, proporcionando una prolongada actividad (Syngenta, 2009 a). La dosis utilizada fue de $3 \mathrm{~cm}^{3}$ por litro de agua.

Neem (Azaridachta indica, A. Juss.) Fam. Meliaceae. Es una planta usada como insecticida, fungicida y nemáticida, su ingrediente activo es la azadirachtina. Actúa por contacto y por 
ingestión, acción que sirve de repelente, efecto anti alimentario, inhibidor del crecimiento, ovoposición y esterilizante, la principal concentración del efecto insecticida está en las semillas. (Rojas et al. 2007). Se utilizó extracto de neem con dosis de $4 \mathrm{~cm}^{3}$ por litro de agua (Jiménez-Martinez y Varela, 2012).

\section{Tratamiento 4: Monarca ${ }^{\circledR}$ alternado con chile + ajo} Monarca (Thiacloprid 9.9\% y Beta-cyfluthrina 1.24\%), Monarca ${ }^{\circledR}$ 112.5 SE. Es una mezcla de dos ingredientes activos con acción sistémica y de contacto, de largo efecto residual. Da protección prolongada contra ataque de plagas transmisoras de virus (Bayer CropScience, 2016). La dosis utilizada fue de $5 \mathrm{~cm}^{3}$ por litro de agua. La preparación del insecticida chile más ajo ya fue descrito en el tratamiento 1 .

Tratamiento 5: Testigo. En este tratamiento se aplicó agua solamente.

\section{Variables evaluadas}

Número de adultos de mosca blanca por planta. Se realizaron muestreos en la totalidad de la planta, principalmente en el envés de la hoja, lugar más frecuentado por el insecto. El muestreo inició a partir de tercer día después del trasplante (ddt), con intervalos de tres días durante las primeras etapas del cultivo y luego cada semana hasta los $63 \mathrm{ddt}$. Se realizaron un total de 12 muestreos.

Porcentaje de incidencia del daño por virosis por planta. Se calculó el porcentaje de plantas con síntomas de daño de virosis con relación al número de plantas muestreadas. Para identificar una planta con síntomas de virosis se observaron signos como mosaico y encrespamiento de las hojas. Para determinar la incidencia de daño de virosis se realizaron tres tomas de datos, a los 25, 45 y 65 ddt. Para obtener el porcentaje de incidencia se utilizó la fórmula planteada por Vanderplank, (1963): \% Incidencia = Total de plantas infestadas/ Total de plantas muestreadas*100.

Porcentaje de severidad del daño de virosis por planta. La severidad es el porcentaje de tejido visualmente dañado o afectado de una planta en un tiempo determinado. Para determinar el grado de severidad se realizaron tres tomas de datos en plantas seleccionadas al azar, las tomas de datos se hicieron a los 25, 45 y 65 ddt. Para determinar el grado de severidad ocasionado por mosca blanca se utilizó la escala de severidad propuesta por Jiménez-Martínez, Lanuza y Rizo, 2012. Para obtener el grado porcentual de la severidad se utilizó la fórmula general planteada por Vanderplank, (1963). $\% \mathrm{~S}=\sum \mathrm{i} / \mathrm{N}(\mathrm{V} \max ) * 100$, Dónde: $\% \mathrm{~S}=$ Porcentaje de severidad, donde $\sum \mathrm{i}=$ Sumatoria de valores observados, $\mathrm{N}=$ Número de plantas muestreadas, $\mathrm{V}_{\max }=$ Valor máximo de la escala de severidad.
Rendimiento del tomate en $\mathbf{k g ~ h a}^{-1}$. A los 75 ddt se realizó un estimado de cosecha para obtener el peso en $\mathrm{kg} \mathrm{ha}^{-1}$, para ello se seleccionaron 10 plantas al azar por parcela y se cosecharon frutos verdes y maduros, luego se pesó el total de tomates de cada parcela, también se contabilizaron los frutos pequeños y botones florales, estas variables se sumaron para calcular el rendimiento total por cada tratamiento.

Análisis económico. Se realizó un análisis económico de presupuesto parcial, análisis de dominancia y tasa de retorno marginal, siguiendo la metodología propuesta por el CIMMYT (1988), la que considera diferentes costos, rendimientos y beneficios.

Análisis de los datos. Una vez recolectados los datos en campo se ordenaron por variable y por tratamiento para luego realizar un análisis de varianza ANDEVA, PROC GLM en SAS, V. 6 (SAS, 1990). Se realizó una separación de medias por Duncan $(p=0.05)$

\section{RESULTADOS Y DISCUSIÓN}

Fluctuación poblacional de mosca blanca. En la Figura 1 se observa que las poblaciones de mosca blanca se presentaron a partir de la primera fecha de muestreo. Los dos picos poblacionales se presentaron a los 24 y 48 dias después del trasplante, a los 24 ddt los mayores promedios se registran en las parcelas donde se aplicó agua (22.42 moscas blancas) y 16.54 individuos donde se aplicó Engeo alternado con chile+ajo+detergente. El tratamiento con menor promedio fue Monarca alternado con Chile+ajo registrando 10.37 moscas blancas por planta. A los 48 ddt el promedio más alto lo presentó el tratamiento Testigo con 11.94 moscas blancas por planta, seguido del tratamiento Imidacloprid alternado con madero negro con 8.89 moscas blancas por planta, y el que presentó el menor promedio de mosca blanca fue el tratamiento Abamectina alternado con Neem con 6.54 moscas blancas por planta.

El análisis de varianza, indica diferencias significativas $(p=0.0001)$ siendo Abamectina alternado con Neem el que registra menor fluctuación poblacional seguido de Monarca alternado con Chile+ajo y Imidacloprid alternado con madero negro (Cuadro 1).

La mosca blanca es una de las plagas que más afecta el desarrollo de una plantación de tomate, ya que puede atacar desde el semillero, hasta un cultivo en fructificación y el daño principal que causa es la transmisión de geminivirus (Jiménez-Martinez y Rodríguez, 2014). Según CATIE (1990), en Nicaragua la mayor incidencia de mosca blanca se presenta en la estación seca del año y en este caso, se registra un incremento durante la canícula, que es un período seco que inicia el 15 de julio y culmina el 15 de agosto. 


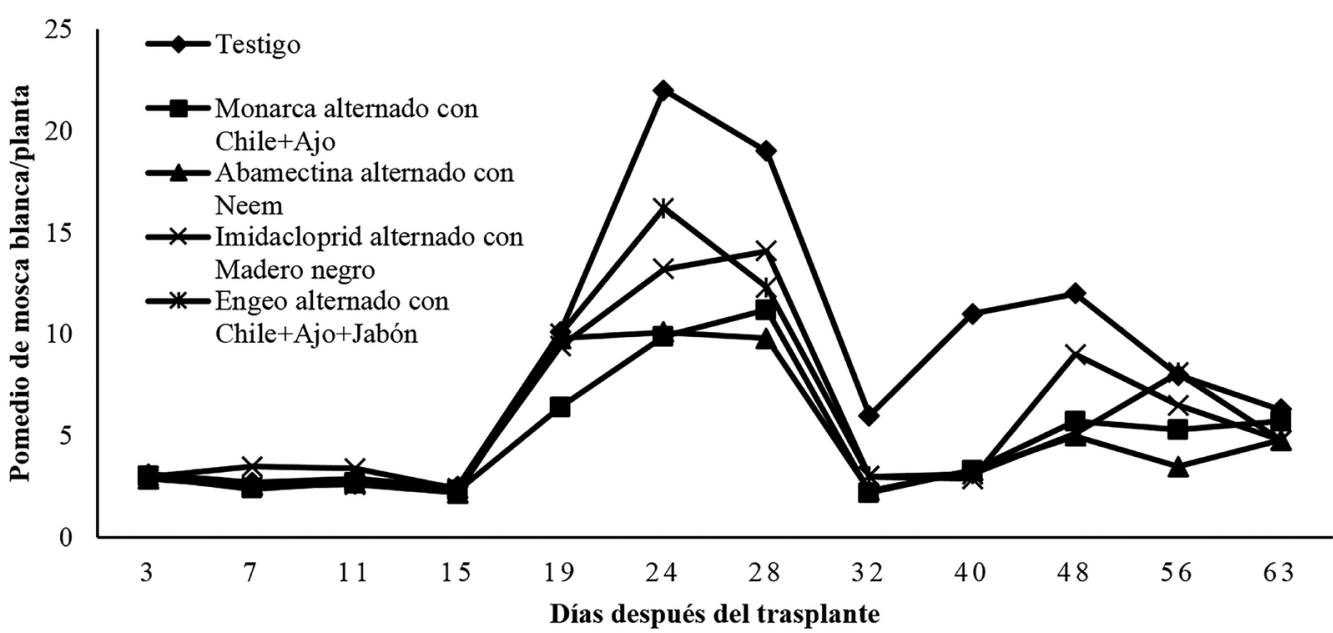

Figura 1. Fluctuación poblacional de mosca blanca en función de los tratamientos

Cuadro 1. Numero de moscas blancas por planta, incidencia y severidad del daño de virosis transmitido por mosca blanca

\begin{tabular}{lccc}
\hline \multicolumn{1}{c}{ Tratamientos } & $\begin{array}{c}\text { Número de mosca } \\
\text { blanca por planta }\end{array}$ & $\begin{array}{c}\text { Incidencia de } \\
\text { virosis (\%) }\end{array}$ & $\begin{array}{c}\text { Severidad de } \\
\text { virosis (\%) }\end{array}$ \\
\cline { 2 - 4 } & Medias \pm ES & Medias \pm ES & Medias \pm ES \\
\hline Abamectina alternado con Neem & $5.45 \pm 0.17 \mathrm{a}$ & $3.33 \pm 1.83 \mathrm{a}$ & $12.84 \pm 6.09 \mathrm{a}$ \\
Monarca alternado con chile+ajo & $5.86 \pm 0.17 \mathrm{~b}$ & $4.88 \pm 0.88 \mathrm{ab}$ & $33.33 \pm 7.21 \mathrm{ab}$ \\
Imidacloprid alternado con madero negro & $6.46 \pm 0.21 \mathrm{bc}$ & $8.00 \pm 2.06 \mathrm{ab}$ & $39.93 \pm 4.04 \mathrm{ab}$ \\
Engeo alternado con chile+ajo+detergente & $6.75 \pm 0.27 \mathrm{~cd}$ & $8.88 \pm 2.56 \mathrm{ab}$ & $41.59 \pm 7.31 \mathrm{~b}$ \\
Testigo & $9.49 \pm 0.30 \mathrm{~d}$ & $10.66 \pm 2.49 \mathrm{~b}$ & $42.12 \pm 7.52 \mathrm{~b}$ \\
\hline $\mathrm{N}$ & 3967.00 & 45.00 & 45.00 \\
C.V & 97.66 & 90.90 & 64.26 \\
$(\mathrm{~F} ; d f ; p)$ & $36.50 ; 3961 ; 0.0001$ & $2.32 ; 40 ; 0.05$ & $3.83 ; 40 ; 0.01$
\end{tabular}

Duncan $=(P: 0.0001)$, ES: Error Estándar, C.V: Coeficiente de variación, N: Número de datos utilizados en el análisis, F: Fischer calculado, $d f$ : Grados de libertad del error, $p$ : Probabilidad según Duncan.

Incidencia del daño por virosis transmitido por mosca blanca. El análisis de varianza indica que existe diferencia significativa $(p=0.05)$ entre los tratamientos, siendo Abamectina alternado con Neem quien presenta menor porcentaje de incidencia de virosis seguido del tratamineto Monarca alternado con chile+ajo (Cuadro 1).

\section{Severidad del daño por virosis transmitido por mosca} blanca $\mathrm{El}$ análisis de varianza indica diferencias significativas $(p=0.01)$ y se registra menor porcentaje de severidad de virosis cuando se aplica Abamectina alternado con Neem con $12.84 \%$, seguido por Monarca alternado con chile+ajo con $33.33 \%$, el tratamiento que presentó mayor porcentaje fue Engeo alternado con chile+ajo+detergente con $41.59 \%$ (Cuadro 1). La mosca blanca causa daños directos al cultivo de tomate, esto debido a la transmisión de Geminivirus causante de virosis del tomate, el cual es capaz de devastar por completo un área determinada del cultivo (Jarquín, 2004).
Según Hilje y Arboleda (1992) los sintomas de virosis trasmitidos por mosca blanca se caracterizan por un amarillamiento general de la planta, un arrugamiento severo de las hojas terminales y enanismo. El daño varía según la raza o biotipo, cuando es alto el número de ninfas y adultos pueden causar daño directo, al debilitar las plantas por la extracción de savia. El daño indirecto es que aún en bajas poblaciones, causa pérdidas severas, por la transmisión de virus como los Carlavirus, Luteovirus, Nepovirus, Potyvirus, Closterovirus y Geminivirus (Hilje y Arboleda 1992), entre los que sobresalen los geminivirus. La virosis causada por la mosca blanca afecta todas las etapas del cultivo del tomate, sin embargo, la etapa de semillero es considerada la más crítica, ya que las plántulas son más susceptibles al virus (Jiménez-Martinez y Rodríguez, 2014). En un estudio realizado en la misma localidad de Tisma, Masaya se evaluaron alternativas de protección física y química de semillero de tomate contra el ataque del complejo mosca blanca-Geminivirus donde el tratamiento de semillero de tomate protegido bajo condiciones de microinvernadero obtuvó resultados de $14 \%$ de incidencia y $8 \%$ de severidad a las 65 días despues del trasplante (Rodriguez y Morales, 2007). Este mismo estudio refleja que el tratamiento Imidacloprid presentó el máximo porcentaje de incidencia y severidad con $56 \%$ y $37 \%$, Imidacloprid alternado con madero negro fue el tratamiento que presentó el mayor porcentaje de incidencia y severidad con 10.66 y $42.12 \%$.

Rendimiento (kg ha $\left.{ }^{-1}\right)$. El mayor rendimiento se obtuvo con las aplicaciones de Abamectina alternada con Neem y los menores con el tratamiento testigo (Figura 2). 


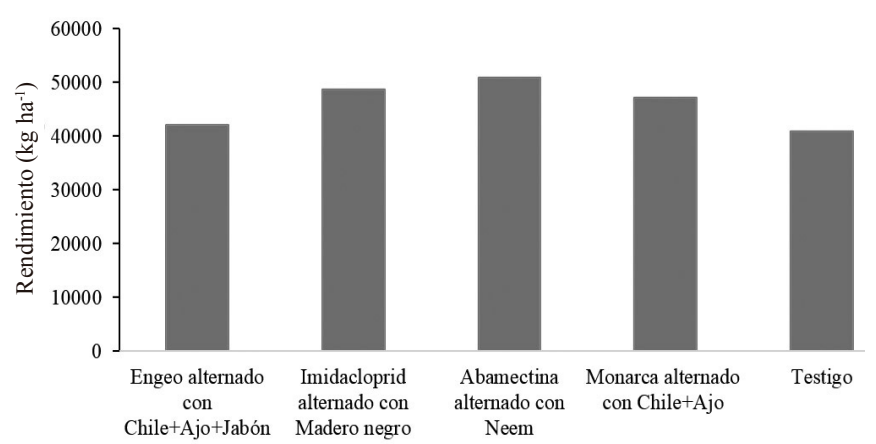

Figura 2. Rendimiento $\left(\mathrm{kg} \mathrm{ha}^{-1}\right)$ por efecto de los tratamientos.

Cerda (2011) encontró que el tratamiento Engeo y madero negro presentaron los mejores rendimientos. Lanuza y Rizo (2012) encontraron que los tratamientos Crisantemo y Engeo fueron los que presentaron los mejores rendimientos, coincidiendo ambos estudios en el tratamiento Engeo, considerando que en este estudio el tratamiento Engeo alternado con Chile+Ajo+Jabón presentó bajos rendimientos. En el estudio realizado por Rodríguez y Morales (2007) encontraron mejores resultados en el tratamiento Imidacloprid, esto coincide con los resultados encontrados en este estudio ya que el Imidacloprid alternado con madero negro obtuvo un buen resultado.

\section{Análisis económico}

Análisis de presupuesto parcial. Se determinó que los mayores costos variables por hectárea (Cuadro 2), se obtienen con aplicaciones de Monarca alternado con chile+ajo (USD 206.16), Engeo alternado con chile+ajo+detergente USD 204.89) e Imidacloprid alternado con madero negro (USD 200.78), y los de menor costos variables por hectárea son el Testigo (USD 143.35) y Abamectina alternado con Neem (USD 188.61). El mayor beneficio neto se obtiene aplicando Abamectina alternado con Neem y el menor cuando se usa agua.

Para realizar el análisis de dominancia (Cuadro 3) se tomó en cuenta el análisis de presupuesto parcial, se consideran los costos variables de cada tratamiento, si los costos variables de un tratamiento están por debajo del beneficio neto de la producción, se considera un tratamiento dominado. El análisis de dominancia indica que Engeo alternado con Chile+Ajo+detergente, Imidacloprid alternado con Madero Negro, y Monarca alternado con Chile+Ajo resultaron ser dominados, esto se debe a que presentan menores beneficios netos y mayores costos variables que el resto de los tratamientos por lo que se excluyen en el análisis de la tasa de retorno marginal.

Cuadro 3. Análisis de dominancia

\begin{tabular}{lccc}
\hline Análisis de dominancia & $\mathrm{CV}$ & $\mathrm{BN}$ & Dominancia \\
\hline Testigo & 133.33 & 25306.37 & $\mathrm{ND}$ \\
$\begin{array}{l}\text { Abamectina alternado } \\
\text { con neem }\end{array}$ & 394.19 & 32366.12 & $\mathrm{ND}$ \\
$\begin{array}{l}\text { Engeo alternado con } \\
\text { chile+ajo+ace }\end{array}$ & 494.43 & 25777.05 & $\mathrm{D}$ \\
$\begin{array}{l}\text { Imidacloprid alternado } \\
\text { con madero negro }\end{array}$ & 548.19 & 30541.98 & $\mathrm{D}$ \\
$\begin{array}{l}\text { Monarca alternado con } \\
\text { chile+ajo }\end{array}$ & 693.57 & 29337.37 & $\mathrm{D}$ \\
\hline
\end{tabular}

CV: Costos variables, BN: Beneficio neto, D: Dominado, ND: No dominado.

Cuadro 2. Presupuesto parcial

\begin{tabular}{|c|c|c|c|c|c|}
\hline Concepto & $\begin{array}{l}\text { Engeo alternado con } \\
\text { el insecticida Chile } \\
\text { +ajo + Jabón }\end{array}$ & $\begin{array}{l}\text { Imidacloprid alternado } \\
\text { con el insecticida } \\
\text { Madero negro }\end{array}$ & $\begin{array}{c}\text { Abamectina alternado } \\
\text { con el insecticida } \\
\text { Extracto de Neem }\end{array}$ & $\begin{array}{l}\text { Monarca alternado } \\
\text { con el insecticida } \\
\text { Chile }+ \text { Ajo }\end{array}$ & Testigo \\
\hline Rendimiento medio $\left(\mathrm{kg} \mathrm{ha}^{-1}\right)$ & 41951.00 & 48561.00 & 50852.00 & 47108.00 & 40810.00 \\
\hline $\begin{array}{l}\text { Rendimiento ajustado (10\%) } \\
\qquad\left(\mathrm{kg} \mathrm{ha}^{-1}\right)\end{array}$ & 37755.90 & 43704.90 & 45766.80 & 42397.20 & 36729.00 \\
\hline Precio de campo (USD) & 0.81 & 0.81 & 0.81 & 0.81 & 0.81 \\
\hline Total de CV (USD ha-1) & 494.43 & 548.19 & 394.19 & 693.57 & 133.33 \\
\hline Beneficio neto (USD ha-1) & 25777.05 & 30541.98 & 32366.12 & 29337.37 & 25306.37 \\
\hline
\end{tabular}


Análisis de la tasa de retorno marginal. Este análisis indica que Abamectina alternado con Neem es el tratamiento más viable económicamente, ya que, por cada dólar invertido, el agricultor obtiene una tasa de retorno marginal de $2706.33 \%$, es decir que, por cada dólar invertido, se recupera el dólar y se obtienen 27.06 dólares adicionales (Cuadro 4).

Cuadro 4. Análisis de la tasa de retorno marginal

\begin{tabular}{lccccc}
\hline Tratamientos & $\begin{array}{c}\text { Costo } \\
\text { variable }\end{array}$ & $\begin{array}{c}\text { Costo } \\
\text { marginal }\end{array}$ & $\begin{array}{c}\text { Beneficio } \\
\text { neto }\end{array}$ & $\begin{array}{c}\text { Beneficio } \\
\text { marginal }\end{array}$ & $\begin{array}{c}\text { TRM } \\
(\%)\end{array}$ \\
\hline Testigo & 133.33 & & 25306.37 & & \\
$\begin{array}{l}\text { Abamectina } \\
\text { alternado con }\end{array}$ & 394.19 & 260.86 & 32366.12 & 7059.75 & 2706.33 \\
Neem & & & & & \\
\hline
\end{tabular}

\section{CONCLUSIONES}

El tratamiento Abamectina alternado con Neem resultó ser el más efectivo para el manejo de mosca blanca y geminivirus en el cultivo de tomate y el económicamente más factible.

Los mejores rendimientos se obtuvieron en los tratamientos Abamectina alternado con Neem, seguido del tratamiento Imidacloprid alternado con madero negro.

\section{AGRADECIMIENTO}

Los autores de esta investigación agradecen a la Sra. Elizabeth González y al Sr. Anuar González, productores de Tisma, Masaya por permitirnos su finca para la realización de la investigación; a la Universidad Nacional Agraria (UNA) por la financiación económica de este estudio.

\section{REFERENCIAS BIBLIOGRÁFICAS}

Arceda Medina, L.E., y López, S.S. (2011). Evaluación de tres insecticidas botánicos botánicos y dos químicos contra el complejo mosca blanca (Bemisia tabaci Gennadius)- Geminivirus en el cultivo de tomate (Lycopersicum sculentum, Mill.), en Tisma-Masaya. (Tesis de grado). Universidad Nacional Agraria, Camoapa, Nicaragua.

Asociación de municipios de Nicaragua. (2005). Municipio: Caracterización de municipios de Masaya. Recuperado de http://www. amunic.org/

Bayer CropScience. (2016). Confidor ${ }^{\circledR}$. Recuperado de http://www.cropscience.bayer.es/Productos/Insecticides/Confidor-20-LS.aspx

Bayer CropScience. (2016). Monarca ${ }^{\circledR} 112,5$ SE. Recuperado de http://www.cropscience.bayer.cl/soluciones/fichaproducto.asp?id=156

Centro Agronómico Tropical de Investigación y Enseñanza. (1990). Guía para el manejo integrado de plagas del cultivo de tomate. Turrialba, Costa Rica: CATIE.

Centro Internacional de Mejoramiento de Maíz y Trigo. (1988). La formulación de recomendaciones a partir de datos agronómicos: Un manual metodológico de evaluación económico. Distrito Federal, México: CIMMYT

Cerda, K.J. (2011). Evaluación de Alternativas de Manejo contra el Complejo Mosca Blanca (Bemisia tabaci Gennadius)- Geminivirus en el cultivo de tomate [Solanum lycopersicum, L. (=Lycopersicum esculentum, Mill.)], en Tisma, Masaya (2009) y Camoapa, Boaco (2010). (Tesis de grado). Universidad Nacional Agraria, Managua, Nicaragua.

Cerda, K.J., y Jiménez-Martínez, E.S. (2012). Alternativas de manejo contra el complejo mosca blanca (Bemisia tabaci Gennadius)geminivirus en el cultivo de tomate (Solanum lycopersicum L. = (Lycopersicum esculentum Mill.) en Tisma, Masaya (2009) Y Camoapa, Boaco (2010). La Calera. 12 (18): 18-28.

González Kuant, J.D., y Obregón Blandón, H.M. (2007). Evaluación de alternativas de protección física y química de semilleros de chiltoma (Capsicum annum L.) contra el ataque del complejo mosca blanca (Bemisia tabaci, Gennadius) - geminivirus. (Tesis de grado). Universidad Nacional Agraria, Managua, Nicaragua.

Hilje, L y Arboleda, O. (1992). Las moscas blancas (Homóptera: Aleyrodidae) en América central y el Caribe. Informe técnico No 205. Turrialba, Costa Rica: CATIE.

Instituto Nicaragüense de Tecnología Agropecuaria. (2002). Cultivo de Tomate con menos riesgos. Recuperado de http://es.scribd.com/ doc/73793591/TOMATE-INTA\#force_seo

Instituto Nicaragüense de Tecnología Agropecuaria. (2004). Manejo Integrado de Plagas: Cultivo de tomate. Managua, Nicaragua: INTA.

Jarquín Palacios, D.A. (2004). Evaluación de cuatro líneas de Tomate (Licopersicum sculentum. Mill), basado en el complejo mosca blanca (Bemisia tabaci)-geminivirus, en la comunidad de Aponpúa, Potosí, Rivas, Nicaragua. (Tesis de maestría). Universidad Nacional Agraria. Managua, Nicaragua.

Jiménez Martínez, E., Lanuza Rodríguez, E.H., y Rizo González, E.J. (2012). Evaluación de productos botánicos y químicos sobre el complejo mosca blanca (Bemisia tabaci Gennadius)- Geminivirus en el cultivo de tomate (Solanum esculentum, Mill.), en TismaMasaya. La Calera 12 (19), 96-106.

Jiménez Martínez, E.S., y Rodríguez Flores, O. (2014). Insectos plagas en cultivos de Nicaragua. Managua, Nicaragua: UNA Jiménez Martínez, E.S., y Varela Ochoa, G. (2012). Módulo práctico: Manejo Integrado de Plagas. Managua, Nicaragua: UNA

Lanuza Rodríguez, E.H., y Rizo González, E.J. (2012). Evaluación de productos botánicos y químicos sobre el complejo mosca blanca (Bemisia tabaci Gennadius)- Geminivirus en el cultivo de tomate (Solanum esculentum, Mill.), en Tisma-Masaya. (Tesis de grado). Universidad Nacional Agraria, Managua, Nicaragua.

Ministerio de Fomento, Industria y Comercio. (2007). Ficha del Tomate. Managua, Nicaragua: MIFIC 
Rayo, M. (2001). Caracterización biológica transmitido por mosca blanca (Bemisia tabaci Genn.) en el cultivo del tomate (Lycopersicum esculentun Mill) en el municipio de Santa Lucía, Boaco. (Tesis de grado). Universidad Nacional Agraria, Managua, Nicaragua.

Ríos Peralta, H.T., y Somarriba Moncada, O.A. (2014). Evaluación de productos botánicos para el manejo del complejo mosca blanca (Bemisia tabaci, Gennadius) - Geminivirus y otros insectos plagas en el cultivo de tomate (Solanum lycopersicum L.), en Tisma, Masaya. (Tesis de grado). Universidad Nacional Agraria, Managua, Nicaragua.

Rodríguez, V., y Morales, J. (2007). Evaluación de alternativas de protección fisico y químico de semilleros de tomate (Lycopersicum esculentum Mill) contra el ataque del complejo mosca blanca (Bemisia tabaciGennandius)- geminivirus y su efecto en el rendimiento, en el municipio de Tisma, Masaya. (Tesis de grado). Universidad Nacional Agraria, Managua, Nicaragua.

Rojas, H.M; Chávez, J.R., Hernández López, C.O., y Tzoy Zapón; M.A. (2007). La etnobiotecnología en el control de plagas en la horticultura de Solalá municipio de Solalá y Almalonga, municipio de Quetzaltenango. San Carlos, Guatemala: USAC.

SAS Institute Inc. (1990). SAS procedures guide, version 6, Third edition, Cary, NC: SAS Intitute Inc.

Syngenta. (2009). Vertimec ${ }^{\circ} 018$ EC. Recuperado de http://www3.syngenta.com/country/cl/cl/soluciones/proteccioncultivos/Documents/Etiquetas/Vertimec018EC.pdf

Syngenta. (2015). Engeo®. Recuperado de http://www3.syngenta.com/country/cl/cl/soluciones/proteccioncultivos/Paginas/Engeo.aspx Vanderplank, J.E. (1963). Plant diseases: epidemilogy and control. New York, Estados Unidos: Academia press 